\title{
EFFECT OF PROCESS PARAMETERS ON DISTORTION AND RESIDUAL STRESS OF HIGH-PRESSURE DIE-CAST AZ91D COMPONENTS
}

\author{
Hoda Dini $\mathbb{1}$, Nils-Eric Andersson, and Anders E. W. Jarfors \\ School of Engineering, Department of Materials and Manufacturing - Casting, Jönköping University, \\ Jönköping, Sweden
}

Copyright (C) 2017 The Author(s). This article is an open access publication

DOI 10.1007/s40962-017-0186-Z

\begin{abstract}
This paper presents a study of distortion and residual stress within a high-pressure die-cast AZ91D component, cast under different processing conditions. The influence of process parameters, i.e., die temperature, cooling time, intensification pressure and first-phase injection speeds,

intensification pressure and the second most important was temperature difference between the two die halves (fixed and moving side). Tensile residual stresses were found very near the surface. Increasing the intensification pressure resulted in an increased level of tensile residual stresses.
\end{abstract} was examined. Distortions were measured using the inhouse standard analog quality control fixture. Residual stress depth profiles were measured using a prism holedrilling method. It was found that the most important process parameter affecting the distortion was
Keywords: magnesium alloy, high-pressure die cast, distortion, residual stress

is more important and effective than injection pressure to decrease porosity of A380 aluminum alloy. Moreover, they reported that the casting with a high injection velocity cannot be preferred together with high pouring temperature, a high-pressure injection with vacuum. Lee et al. ${ }^{7}$ showed that for magnesium alloy porosity is reduced with increasing intensification pressure, but increased with increasing casting second-phase injections speed.

Besides porosity, distortion (warping) of the casting is another cause of rejection for HPDC parts. A component may exceed the accepted tolerance allowance due to distortion. ${ }^{10}$ Distortions in castings are usually due to variation of cooling rates in different regimes or due to variation of section thicknesses. ${ }^{11}$ Castings contract during solidification and cooling. This contraction interacts with constraints such as die walls and generates residual stresses and a complex springback and continued warping during post-die ejection cooling. ${ }^{12}$ For complex-shaped castings, non-uniform cooling conditions may create plastic strain that results in permanent distortion. ${ }^{13}$

Solidification and cooling in the HPDC process lead to the development of residual stresses within the surface layers 
of the cast component. This has a negative influence on, for instance, fatigue life. ${ }^{14}$ Not only the level of stress, but also the type of stress (tensile or compressive) is critical factors to understand in the formation of residual stress. A surface with tensile residual stress induced by the casting process will be more prone to fatigue failure than a surface with compressive residual stress. ${ }^{15}$ Moreover, if substantial residual stress exists in a casting, there is potential that at high temperatures residual stress may relax, resulting in part distortion. ${ }^{16}$ Hence, understanding of residual stress distribution and the distortion pattern of HPDC cast AZ91D parts could enable reduced shape deviation from design specification, through improved process control and better die design. This would also improve productivity and reduce cost. Hence, to increase the process efficiency a fundamental understanding of component distortion and residual stress is an important topic to study. Specifying the appropriate set of process parameters, which provides a high-quality HPDC product, is a key concern for engineers and researchers.

The main objective of present work was to get a detailed map and to understand the effect of HPDC process parameters on both distortion and residual stress response of an AZ91D component. The studied parameters were first-phase injection speed, the temperature difference between the two die halves through variation of the temperature of fixed half of the die, cooling time and intensification pressure. The distortion and residual stress of the finished products were measured. Furthermore, analysis of variance (ANOVA) was used to find the effect of casting parameters on the performance characteristics.

\section{Experimental Procedure}

\section{Component Casting}

The case study of this paper is an engine crank case of a chain saw, as shown in Figure 1. The composition of the alloy was measured using an optical emission spectroscopy (OES) (SpectroMaxCCD LMXM3, SPECTRO Analytical Instruments Inc, Germany), as given in Table 1. Crank cases were manufactured at Husqvarna $\mathrm{AB}$ using a Buhler SC-D42 machine with $4000 \mathrm{kN}$ locking force, and the protecting gas was a mixture of $0.5 \% \mathrm{SO}_{2}$ and dry air. The experimental window for the design is shown in Table 2.

In HPDC, there are a number of parameters that may influence component characteristics and performance. Hence, investigating the best combinations of process parameters and their changing quantities in order to obtain results statistically reliable is crucial. In the current study, a response surface method was used through a D-optimal approach allowing for an effective design capable of a quadratic response surface with three replications and three runs for the lack of fit. To create this design of experiments (DOE), DesignExpert ${ }^{\mathrm{TM}}$ software (Stat-Ease) was used for both the DOE and the regression analysis and analysis of variance (ANOVA). In current work, four principal casting parameters (A) first-phase injection speed, (B) temperature of fixed half of the die, (C) cooling time and (D) intensification pressure were specified as the varied casting parameters. The choice of omitting the second-phase injection speed was based on the fact that the dwell time in the shot sleeve is of the order 70 times longer than the duration of the second phase resulting in that the temperature loss during the process is dominated by the shotchamber dwell time. The interfacial heat flux in the shot sleeve is of the order of $2 \mathrm{MW} / \mathrm{m}^{217}$ and in order of $6 \mathrm{MW} /$ $\mathrm{m}^{218}$ in the die cavity during filling; hence, shot-sleeve dwell time is the dominating parameter for final part temperature during processing. The minimum and maximum levels of HPDC parameters are identified as given in Table 2. The interaction between these parameters was studied as well. It should be mentioned that intensification pressure was applied immediately after the second stage and for the full duration of the cooling time. To assure that components were cast under stable conditions, parts from the first ten shots were scrapped and subsequently components were sampled. Moreover, it was assured that all the test conditions made acceptable cast components without apparent casting defects and within dimensional tolerances.

The experimental design and results are collated in Tables 3 and 4 for distortion and residual stress

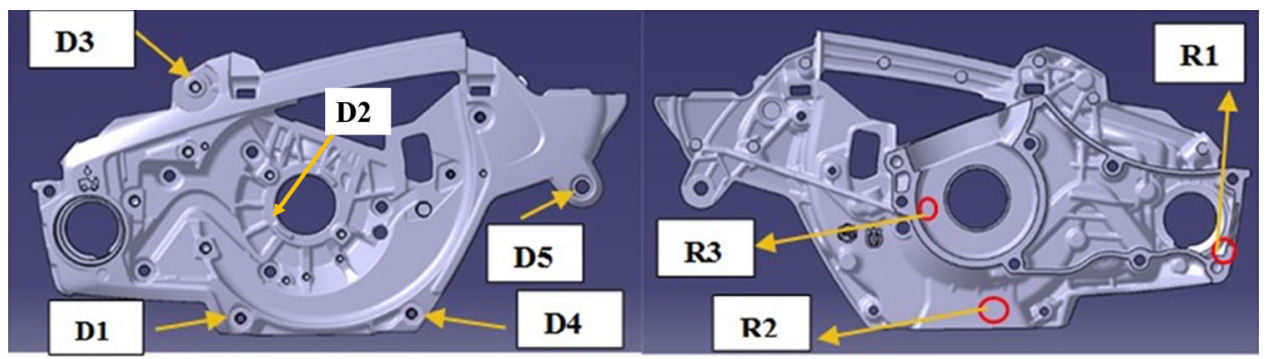

Figure 1. Illustration of the crank case. The right picture is moving side and the left picture is fixed side of the crank case. The points for distortion measurements are indicated as D1, D2, D3, D4 and D5. The locations for residual stress measurements are indicated as $R 1, R 2$ and $R 3$. 
Table 1. Chemical Composition of the AZ91D Alloy (wt\%) Established Through OES

\begin{tabular}{llllllll}
\hline $\mathrm{Mg}$ & $\mathrm{Al}$ & $\mathrm{Zn}$ & $\mathrm{Mn}$ & $\mathrm{Fe}$ & $\mathrm{Ni}$ & $\mathrm{Cu}$ & $\mathrm{Si}$ \\
\hline Balance & $8.5 \pm 0.2$ & $0.67 \pm 0.3$ & $0.25 \pm 0.1$ & $0.0023 \pm 0.01$ & $0.0017 \pm 0.005$ & $0.021 \pm 0.03$ & $0.017 \pm 0.1$ \\
\hline
\end{tabular}

measurements, respectively. For distortion measurements, each run condition was repeated ten times to acquire sufficient statistics for the response. Residual stress was

Table 2. Design Scheme of High-Pressure Die-Cast Parameters and Their Minimum and Maximum Levels Together with Average of Reference Level Parameters for References Cast Sample

\begin{tabular}{llllll}
\hline Symbol & HPDC parameter & Unit & $\begin{array}{l}\text { Min. } \\
\text { level }\end{array}$ & $\begin{array}{l}\text { Max. } \\
\text { level }\end{array}$ & $\begin{array}{l}\text { Ref. } \\
\text { level }\end{array}$ \\
\hline A & $\begin{array}{c}\text { First-phase injection } \\
\text { speed }\end{array}$ & $\mathrm{m} / \mathrm{s}$ & 1.5 & 4.5 & 1.5 \\
B & $\begin{array}{l}\text { Temperature of fixed half } \\
\text { of the die }\end{array}$ & ${ }^{\circ} \mathrm{C}$ & 100 & 220 & 220 \\
C & $\begin{array}{l}\text { Cooling time } \\
\text { Intensification pressure }\end{array}$ & $\mathrm{S}$ & 5 & 15 & 7 \\
B & Bar & 450 & 1100 & 824 \\
\hline
\end{tabular}

measured for components cast by eight different run conditions where each run was repeated three times, see Table 4.

\section{Component Distortion Measurements}

The distortion value was measured by using the standard in-house quality assurance tool, as shown in Figure 2. The distortion values were obtained through the comparison of dimensional measurement between actual HPDC part and design specification at five critical reference points D1, D2, D3, D4 and D5, see Figures 1 and 2. The measured direction was along the normal vector of surface, and the value measured was the positive (toward fixed side) or negative (toward moving side) deviation away from the zero plane.

Table 3. Experimental Layout Using Quadratic Method Through DOE Together with Distortion Responses at Different Reference Points

\begin{tabular}{lllllrlrrr}
\hline $\begin{array}{l}\text { EXP } \\
\text { no. }\end{array}$ & $\begin{array}{l}\mathrm{A} \\
(\mathrm{m} / \mathrm{s})\end{array}$ & $\begin{array}{l}\mathrm{B} \\
\left({ }^{\circ} \mathrm{C}\right)\end{array}$ & $\begin{array}{l}\mathrm{C} \\
(\mathrm{s})\end{array}$ & $\begin{array}{l}\mathrm{D} \\
(\mathrm{Bar})\end{array}$ & $\begin{array}{l}\text { Point } \mathrm{D} 1 \\
\left(10^{-2} \mathrm{~mm}\right)\end{array}$ & $\begin{array}{l}\text { Point } \mathrm{D} 2 \\
\left(10^{-2} \mathrm{~mm}\right)\end{array}$ & $\begin{array}{l}\text { Point } \mathrm{D} 3 \\
\left(10^{-2} \mathrm{~mm}\right)\end{array}$ & $\begin{array}{l}\text { Point } \mathrm{D} 4 \\
\left(10^{-2} \mathrm{~mm}\right)\end{array}$ & \multicolumn{1}{c}{$\begin{array}{l}\text { Point } \mathrm{D} 5 \\
\left(10^{-2} \mathrm{~mm}\right)\end{array}$} \\
\hline 1 & 3.07 & 220 & 15 & 684.93 & $4.75 \pm 0.21$ & $-3.75 \pm 0.19$ & $-17.68 \pm 0.29$ & $2.31 \pm 0.15$ & $6.32 \pm 0.11$ \\
2 & 1.5 & 220 & 15 & 1100 & $10.43 \pm 0.24$ & $-2.56 \pm 0.15$ & $-20.12 \pm 0.31$ & $7.25 \pm 0.33$ & $-4.15 \pm 0.12$ \\
3 & 4.5 & 220 & 5 & 1100 & $9.43 \pm 0.27$ & $0.43 \pm 0.15$ & $-21.62 \pm 0.55$ & $6.18 \pm 042$ & $-5.21 \pm 0.41$ \\
4 & 1.5 & 220 & 5 & 450 & $7.62 \pm 0.17$ & $-2.93 \pm 0.32$ & $-20.5 \pm 0.35$ & $2.5 \pm 0.48$ & $3.32 \pm 0.24$ \\
5 & 4.5 & 220 & 9.75 & 450 & $7.6 \pm 0.47$ & $-2.3 \pm 0.15$ & $-19.6 \pm 0.22$ & $4.7 \pm 0.39$ & $4.2 \pm 0.32$ \\
6 & 1.5 & 205.6 & 10.5 & 752.25 & $9.5 \pm 0.42$ & $-3.3 \pm 0.15$ & $-21.4 \pm 0.61$ & $2.9 \pm 0.27$ & $9.33 \pm 0.21$ \\
7 & 4.5 & 197.2 & 15 & 1100 & $8.5 \pm 0.65$ & $-3.6 \pm 0.33$ & $-20.5 \pm 0.5$ & $5.7 \pm 0.44$ & $-3.79 \pm 0.4$ \\
8 & 4.5 & 197.2 & 15 & 1100 & $8.7 \pm 0.51$ & $-3.6 \pm 0.4$ & $-20.6 \pm 0.52$ & $5.7 \pm 0.53$ & $-3.5 \pm 0.84$ \\
9 & 2.67 & 173.2 & 8.85 & 1100 & $10.3 \pm 0.15$ & $-2.6 \pm 0.22$ & $-22.5 \pm 0.54$ & $7.6 \pm 0.45$ & $0.4 \pm 0.16$ \\
10 & 1.5 & 161.8 & 15 & 450 & $7.5 \pm 0.22$ & $-4.9 \pm 0.23$ & $-20 \pm 0.21$ & $3.84 \pm 0.2$ & $13.35 \pm 0.67$ \\
11 & 1.5 & 161.8 & 15 & 450 & $7 \pm 0.25$ & $-5.2 \pm 0.32$ & $-19.7 \pm 0.44$ & $3.8 \pm 0.38$ & $12.84 \pm 0.63$ \\
12 & 4.5 & 157.6 & 5 & 684 & $8.8 \pm 0.32$ & $0.1 \pm 0.23$ & $-20.3 \pm 0.3$ & $7.35 \pm 0.3$ & $13.85 \pm 0.41$ \\
13 & 1.98 & 154 & 5 & 749 & $9.2 \pm 0.2$ & $-1.4 \pm 0.22$ & $-21.9 \pm 0.37$ & $6.54 \pm 0.26$ & $14.8 \pm 0.42$ \\
14 & 3.88 & 147.83 & 12 & 778.82 & $7 \pm 0.44$ & $-2.4 \pm 0.22$ & $-20 \pm 0.68$ & $6.93 \pm 0.23$ & $14.98 \pm 0.59$ \\
15 & 4.5 & 100 & 15 & 450 & $6.43 \pm 0.15$ & $-4.06 \pm 0.17$ & $-19.25 \pm 0.19$ & $4.62 \pm 0.34$ & $9.99 \pm 0.61$ \\
16 & 4.5 & 100 & 6.8 & 1100 & $8.5 \pm 0.22$ & $-2 \pm 0.21$ & $-22.4 \pm 0.22$ & $4.57 \pm 0.26$ & $-4.04 \pm 0.21$ \\
17 & 2.1 & 100 & 15 & 1100 & $11.6 \pm 0.3$ & $-3.2 \pm 0.24$ & $-20.8 \pm 0.48$ & $6.06 \pm 0.29$ & $-3.33 \pm 0.15$ \\
18 & 4.5 & 100 & 15 & 450 & $7.43 \pm 0.15$ & $-4 \pm 0.15$ & $-18.87 \pm 0.23$ & $3.75 \pm 0.17$ & $8.26 \pm 0.17$ \\
19 & 1.5 & 100 & 5 & 1100 & $10.06 \pm 0.14$ & $-2.18 \pm 0.2$ & $-22.18 \pm 0.35$ & $2.25 \pm 0.41$ & $-3.67 \pm 0.49$ \\
20 & 1.5 & 100 & 10.25 & 693.75 & $7.25 \pm 0.11$ & $-3.68 \pm 0.11$ & $-21.5 \pm 0.42$ & $1 \pm 0.22$ & $8.70 \pm 0.11$ \\
21 & 2.91 & 100 & 5 & 450 & $8.8 \pm 0.29$ & $-2.8 \pm 0.32$ & $-19.3 \pm 0.42$ & $0.9 \pm 0.17$ & $8.73 \pm 0.26$ \\
\hline
\end{tabular}

Parameters are $A=$ first-phase injection speed, $B=$ temperature of fixed half of the die, $C=$ cooling time and $D=$ intensification pressure 
Table 4. Experimental Layout and Responses for Residual Stresses

\begin{tabular}{|c|c|c|c|c|c|c|c|c|}
\hline Run no. & Rep no. & $\begin{array}{l}\text { First-phase } \\
\text { injection } \\
\text { speed }(\mathrm{m} / \mathrm{s})\end{array}$ & $\begin{array}{l}\text { Temperature } \\
\text { of fixed half } \\
\text { of the die }\left({ }^{\circ} \mathrm{C}\right)\end{array}$ & $\begin{array}{l}\text { Cooling } \\
\text { time (s) }\end{array}$ & $\begin{array}{l}\text { Intensification } \\
\text { pressure (bar) }\end{array}$ & $\begin{array}{l}\text { Response } \\
\text { for point } 1 \\
\text { (MPa) }\end{array}$ & $\begin{array}{l}\text { Response } \\
\text { for point } 2 \\
\text { (MPa) }\end{array}$ & $\begin{array}{l}\text { Response } \\
\text { for point } 3 \\
\text { (MPa) }\end{array}$ \\
\hline \multirow[t]{3}{*}{1} & 1 & 3.07 & 220 & 15 & 684.93 & 25.45 & 45.12 & 18.9281 \\
\hline & 2 & 3.07 & 220 & 15 & 684.93 & 20.5645 & 40.5 & 14.0426 \\
\hline & 3 & 3.07 & 220 & 15 & 684.93 & 20.54 & 40.32 & 14.0181 \\
\hline \multirow[t]{3}{*}{2} & 1 & 1.5 & 220 & 15 & 1100 & 44.5863 & 64.52 & 38.0644 \\
\hline & 2 & 1.5 & 220 & 15 & 1100 & 49.1655 & 59.30 & 42.6436 \\
\hline & 3 & 1.5 & 220 & 15 & 1100 & 45.25 & 55.14 & 38.7281 \\
\hline \multirow[t]{3}{*}{3} & 1 & 4.5 & 220 & 5 & 1100 & 49.0191 & 69.25 & 42.4972 \\
\hline & 2 & 4.5 & 220 & 5 & 1100 & 44.2448 & 64.62 & 37.7229 \\
\hline & 3 & 4.5 & 220 & 5 & 1100 & 42.236 & 62.51 & 35.7141 \\
\hline \multirow[t]{3}{*}{4} & 1 & 1.5 & 220 & 5 & 450 & 14 & 39.81 & 14.5539 \\
\hline & 2 & 1.5 & 220 & 5 & 450 & 18.2011 & 42.30 & 11.6792 \\
\hline & 3 & 1.5 & 220 & 5 & 450 & 19.5445 & 40.28 & 13.0226 \\
\hline \multirow[t]{3}{*}{5} & 1 & 1.5 & 205.6 & 10.5 & 752.25 & 25.299 & 45.15 & 18.7771 \\
\hline & 2 & 1.5 & 205.6 & 10.5 & 752.25 & 24.08 & 44.46 & 18 \\
\hline & 3 & 1.5 & 205.6 & 10.5 & 752.25 & 23.544 & 43.36 & 17.0221 \\
\hline \multirow[t]{3}{*}{6} & 1 & 4.5 & 100 & 15 & 450 & 20.5 & 40.54 & 13.9781 \\
\hline & 2 & 4.5 & 100 & 15 & 450 & 18 & 35 & 11.4781 \\
\hline & 3 & 4.5 & 100 & 15 & 450 & 19.526 & 36.58 & 13.4 \\
\hline \multirow[t]{3}{*}{7} & 1 & 1.5 & 100 & 5 & 1100 & 52.54 & 72.32 & 46.0181 \\
\hline & 2 & 1.5 & 100 & 5 & 1100 & 55.54 & 75.24 & 47.0181 \\
\hline & 3 & 1.5 & 100 & 5 & 1100 & 50.54 & 70.65 & 44.0181 \\
\hline \multirow[t]{3}{*}{8} & 1 & 1.5 & 100 & 10.25 & 693.75 & 25 & 45 & 18.4781 \\
\hline & 2 & 1.5 & 100 & 10.25 & 693.75 & 24.32 & 44.41 & 17.7981 \\
\hline & 24 & 1.5 & 100 & 10.25 & 693.75 & 28.545 & 48.28 & 22.0231 \\
\hline
\end{tabular}

\section{Residual Stress Measurements}

The prism hole-drilling system (Stresstech Group Company) was employed to measure residual stresses. The hole-drilling technique involves drilling a hole in the component and measuring the resulting strain near the hole. The hole-drilling technique is based on the fact that if a stressed material is removed from its surroundings, the equilibrium of the surrounding material must readjust its stress state to attain a new equilibrium. In the conventional

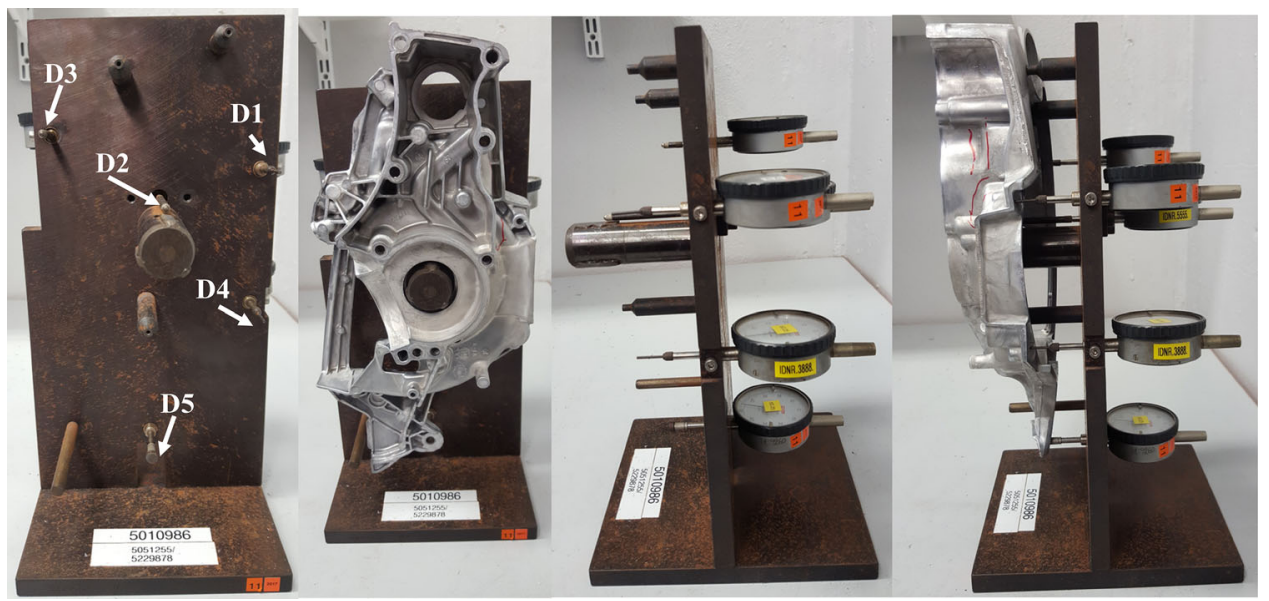

Figure 2. The standard in-house quality assurance tool applied for measuring the distortion value. $D 1, D 2, D 3, D 4$ and $D 5$ are the five reference points. 
Table 5. ANOVA Response Surface Reduced Quadratic Model for Distortion Response at Point D5

\begin{tabular}{lllllll}
\hline Source & $\begin{array}{l}\text { Sum of } \\
\text { squares }\end{array}$ & $d f$ & $\begin{array}{l}\text { Mean } \\
\text { square }\end{array}$ & $F$ value & $\begin{array}{l}p \text { value } \\
\text { Prob }>F\end{array}$ \\
\hline Model & 34.30 & 5 & 6.86 & 166.00 & $<0.0001$ & Significant \\
B-temperature of fixed half of the die & 1.04 & 1 & 1.04 & 25.21 & 0.0002 & Significant \\
D_intensification pressure & 18.43 & 1 & 18.43 & 446.08 & $<0.0001$ & Significant \\
BD & 0.034 & 1 & 0.034 & 0.82 & 0.3792 & Kept for model hierarchy \\
B $^{2}$ & 3.26 & 1 & 3.26 & 79.01 & $<0.0001$ & Significant \\
D $^{2}$ & 4.59 & 1 & 4.59 & 110.98 & $<0.0001$ & Significant \\
Residual & 0.62 & 15 & 0.041 & & & Not significant \\
Lack of fit & 0.59 & 12 & 0.049 & 4.61 & 0.1174 & \\
Pure error & 0.032 & 3 & 0.011 & & &
\end{tabular}
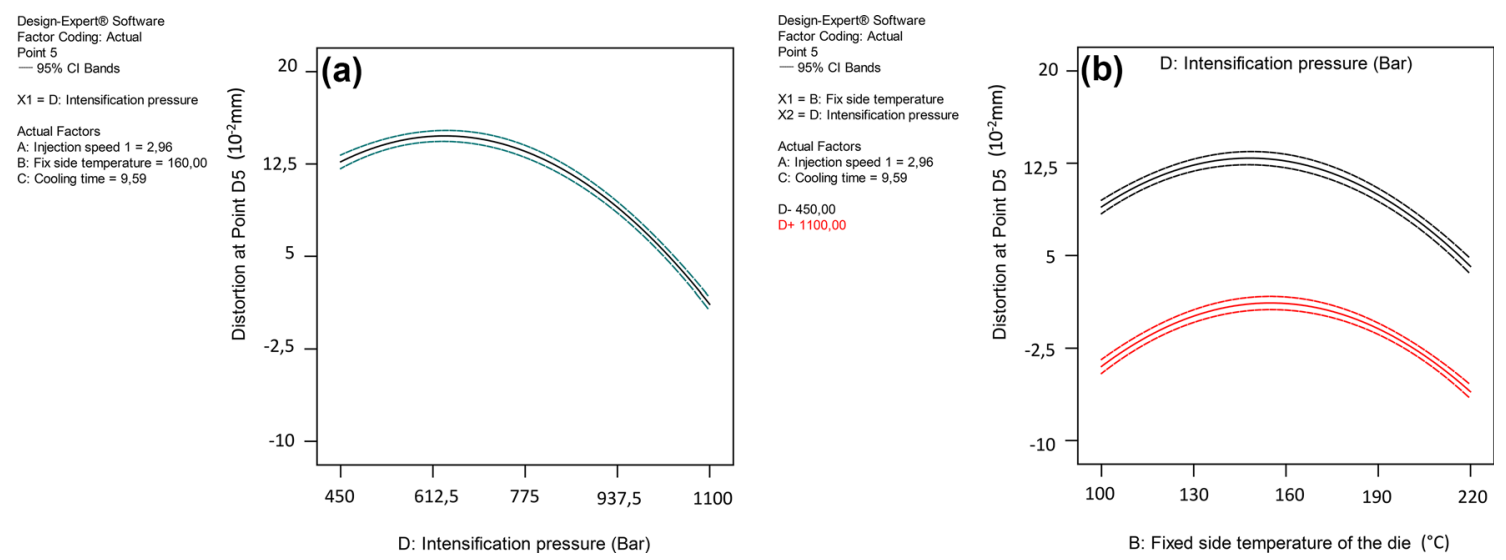

Figure 3. The effect of (a) parameter $(D)=$ intensification on distortion response and (b) interaction of parameters $(B)=$ temperature of fixed half of the die and parameter $(D)$ on distortion response at point D5. Centerline is the actual trend. Dash lines are the $95 \%$ confidence intervals.

technique using strain gages, surface distortion is measured as a change in electrical resistance. ${ }^{19}$ Prism measures surface distortion using laser light (ESPI-electronic speckle pattern interferometry). ${ }^{20}$ Images from before drilling are compared with those after each incremental drilling. Every condition is described by a set of four images, each taken with the reference beam phase-shifted a different amount: $0^{\circ}, 90^{\circ}, 180^{\circ}$ and $270^{\circ}$.

Data analysis includes all pixels in a ring-shaped region around the hole, described by the inner and outer integration radius (the inner radius was twice that of the hole radius and the outer radius was four times of the hole radius). The area immediately next to the edge does not provide useful information because the drilling process disturbs this part of the surface. Eventually, the results were treated with an unwrapping algorithm to produce the displacement map for each of the three variables of the planar stress state. Furthermore, together with the elastic material parameters, Young's modulus and Poisson's ratio, this generates the stress values.
The maximum useful hole depth is dependent on hole diameter. The numerical models developed for prism support drilling between drilling between $0.1<h / d<0.6$. The end mills with $0.8 \mathrm{~mm}$ dimeter were used in this study.

In current study, residual stresses were measured at three different locations, points R1, R2 and R3, as shown in Figure 1. These points are the critical points, which have shown failure (creep and/or fatigue) problem during operation. The maximum residual stress value at any depth was adopted as the residual stress value of the whole product in this process. The drilling rig was programmed to reach the final depth of $0.5 \mathrm{~mm}$ in 14 equidistant steps. The drilling feed rate was $0.05 \mathrm{~mm} / \mathrm{s}$, and after every drilling step, the drilling was stopped for about $60 \mathrm{~s}$ before taking a first set of images; a second image set was taken about $30 \mathrm{~s}$; after that, illumination alpha rotation angle was $50^{\circ}$ and video alpha rotation angle was $30^{\circ}$ for all measurements. Stresses were calculated using a Poisson's ratio of 0.3 and a Young's modulus of 45,000 MPa. 


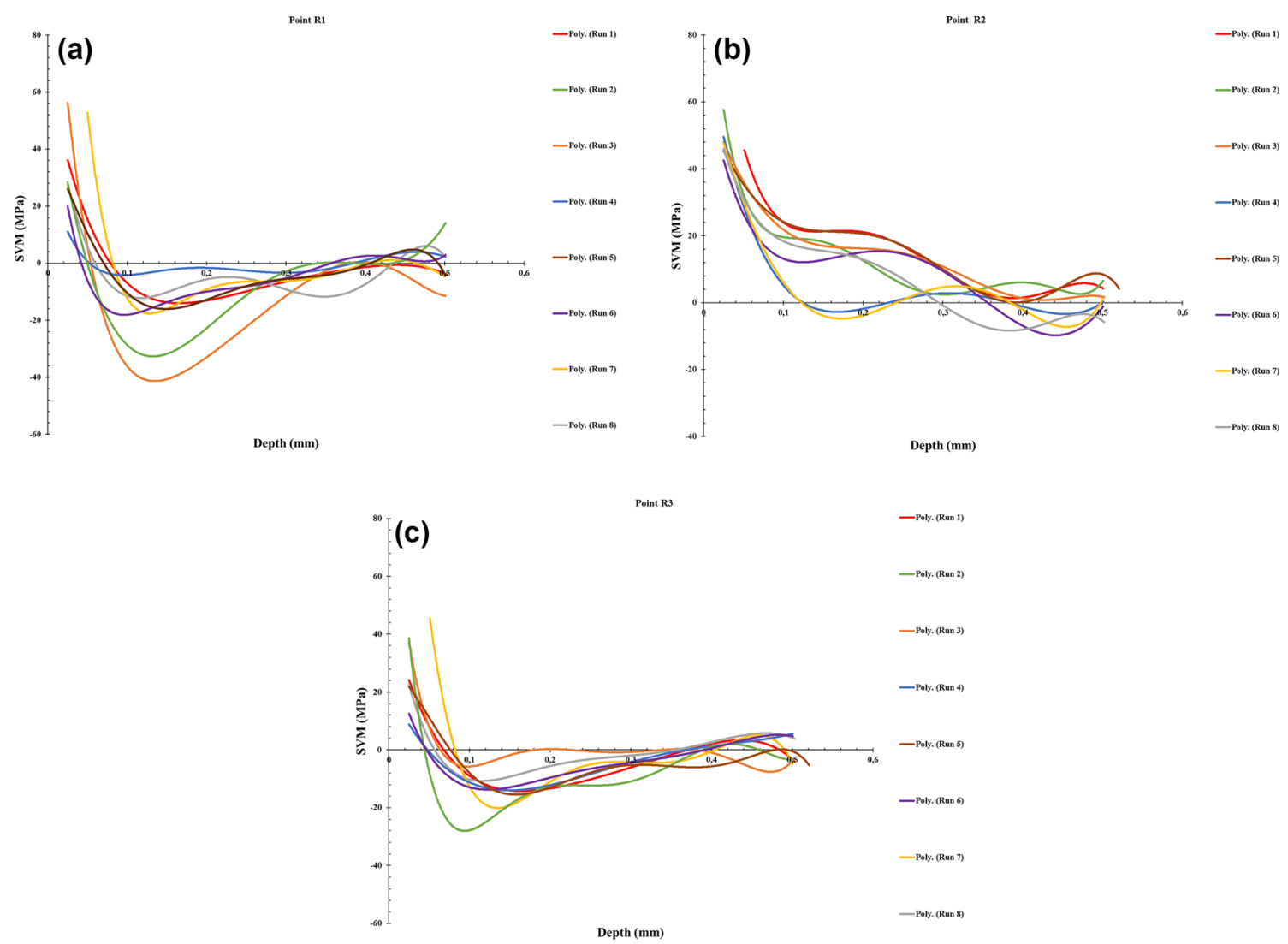

Figure 4. Trends of residual stress profiles of the SVM stress at (a) point 1, (b) point 2 and (c) point 3. The run conditions are given in Table 4.

Table 6. ANOVA Response Surface Reduced Quadratic Model for Residual Stress Responses for Point R1

\begin{tabular}{lllllll}
\hline Source & Sum of Squares & $d f$ & Mean square & $F$ value & $p$-value prob $>F$ \\
\hline Model & 3836.97 & 4 & 959.24 & 203.89 & $<0.0001$ & Significant \\
B-temperature of fixed half of the die & 82.06 & 1 & 82.06 & 17.44 & 0.0006 & Significant \\
D_intensification pressure & 2807.46 & 1 & 2807.46 & 596.75 & $<0.0001$ & Significant \\
BD & 33.93 & 1 & 33.93 & 7.21 & 0.0151 & Significant \\
D2 & 207.26 & 1 & 207.26 & 44.06 & $<0.0001$ & Significant \\
Residual & 84.68 & 18 & 4.70 & & & Not significant \\
Lack of fit & 3.51 & 3 & 1.17 & 0.22 & 0.8837 & \\
Pure error & 81.17 & 15 & 5.41 & & &
\end{tabular}

In this study, the signed von Mises stress (SVM) was used for the residual stresses quantification, see Eq. 1. The SVM represents the sign (positive or negative) of the absolute maximum principal stress to include the influence of tension and compression in the effective stress.

$\sigma_{\mathrm{svm}}=\operatorname{sign}\left(I_{1}\right) \cdot \sigma_{\mathrm{vm}}$

Eqn. 1

where $\sigma_{\mathrm{vm}}$ is the von Mises stress and $I_{1}=\sigma_{x}+\sigma_{y}+\sigma_{z}$

\section{Result and Discussion}

\section{Analysis of Distortion}

The average distortion (together with standard errors) responses at each reference points (see Figure 1) are collated in Table 3. The distortion direction was also taken into consideration. To model the significance of HPDC process parameters and their interactions on distortion responses at different reference points, regression analysis was applied through ANOVA. However, no statistically significant regression model was realized for the distortion 
Table 7. ANOVA Response Surface Reduced Quadratic Model for Residual Stress Responses for Point R2

\begin{tabular}{lcccccc}
\hline Source & Sum of squares & $d f$ & Mean square & $F$ value & $p$-value prob $>F$ \\
\hline Model & 3558.31 & 4 & 889.58 & 119.67 & $<0.0001$ & Significant \\
B-temperature of fixed half of the die & 141.05 & 1 & 141.05 & 18.97 & 0.0003 & Significant \\
C-cooling time & 247.00 & 1 & 247.00 & 33.23 & $<0.0001$ & Significant \\
C $^{2}$ & 109.94 & 1 & 109.94 & 14.79 & 0.0011 & Significant \\
D-intensification pressure & 2447.02 & 1 & 2447.02 & 329.17 & $<0.0001$ & Significant \\
Residual & 141.24 & 19 & 7.43 & & & Not significant \\
Lack of fit & 13.62 & 3 & 4.54 & 0.57 & & 0.6433 \\
Pure error & 127.62 & 16 & 7.98 & & &
\end{tabular}

Table 8. ANOVA Response Surface Reduced Quadratic Model for Residual Stress Responses for Point R3

\begin{tabular}{lcccccc}
\hline Source & Sum of squares & $d f$ & Mean square & $F$ value & $p$-value prob $>F$ \\
\hline Model & 4321.29 & 2 & 2160.65 & 118.83 & $<0.0001$ & Significant \\
B-temperature of fixed half of the die & 179.57 & 1 & 179.57 & 9.88 & 0.0049 & Significant \\
D-intensification pressure & 4301.37 & 1 & 4301.37 & 236.56 & $<0.0001$ & Significant \\
Residual & 381.85 & 21 & 18.18 & & \multirow{2}{*}{ No.3967 significant } \\
Lack of fit & 118.14 & 6 & 19.69 & 1.12 & & \\
Pure error & 263.70 & 15 & 17.58 & & & \\
Cor total & 4703.14 & 23 & & & &
\end{tabular}

responses at points D1, D2, D3 and D4. The reason for this could be related to the relatively small changes in distortion responses of these points by varying the cast conditions, see Table 3.

On the other hand, for distortion responses at point D5, the ANOVA was conducted and the results are given in Table 5. The temperature of fixed half of the die, (B), and intensification pressure parameter, (D), were statistically significant model terms. Moreover, the parameters $\left(\mathrm{B}^{2}\right)$ and $\left(\mathrm{D}^{2}\right)$ were also statistically significant. Based on ANOVA results, the interaction between the temperature of fixed half of the die parameter (B) and intensification pressure parameter (D) was kept to keep model hierarchy to allow retransformation from the normalized terms used in the evaluation. It should be mentioned that another model where parameters (A) and (C) were statistically significant could be obtained but removed as they had no physically significant impact on distortion.

The impact of the intensification pressure on distortion responses is plotted in Figure $3 \mathrm{a}$. Increasing the intensification pressure generated less distortion at point D5. Increasing the intensification pressure will increase heat transfer between the part and the die. This will allow the part rib structure on the moving side to bend the part toward the moving side.
Figure $3 b$ shows the impact of the interaction of the temperature of fixed half of the die, (B), and intensification pressure, (D), on distortion responses at point D5. The temperature of the moving side was kept constant at $150{ }^{\circ} \mathrm{C}$ during the experimental campaign. It was observed that as the temperature difference between the two die halves (fixed and moving side) increased, the distortion response was such that the distortion tended to be toward the moving side at point D5.

The largest distortion in the part was at point D3. The distortions did not significantly change with casting conditions, see Table 3. Moreover, no statistically significant model was obtained for distortion responses at this point. It should, however, be noted that point D3 was adjacent to two ejector pins and there was a rib structure on the moving side that could contribute to this distortion. The exact cause of this large distortion could not be positively identified.

\section{Analysis of Residual Stress Measurements Analysis}

Figure $4 \mathrm{a}-\mathrm{c}$ shows the SVM stresses at the locations points R1, R2 and R3 with locations shown in Figure 1. The maximum value of von Mises (VM) stress at any depth was identified and the SVM value of that VM stress was considered as the residual stress value of the component. The residual stress responses are collated in Table 4. It was 


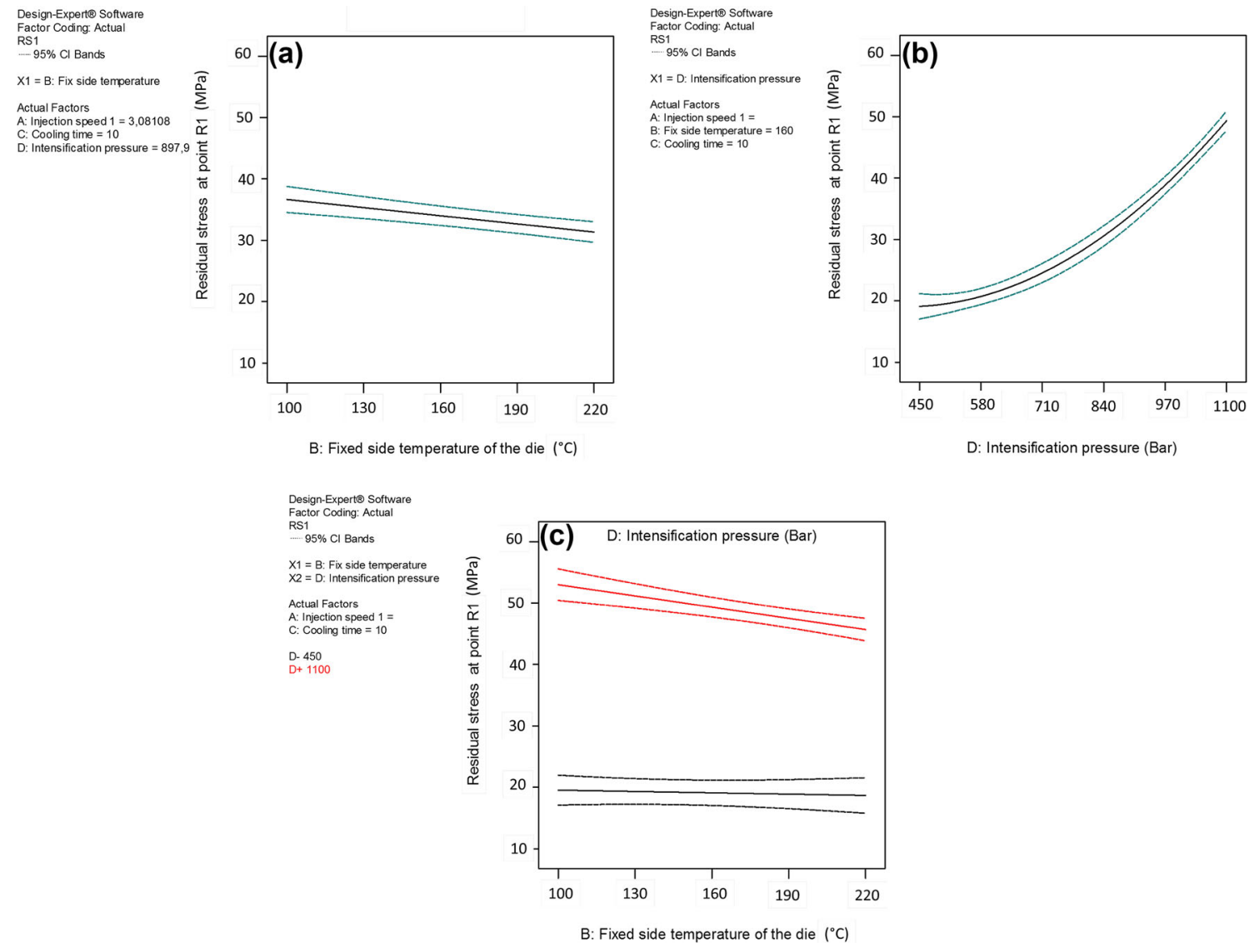

Figure 5. (a) The effect of parameter (B) temperature of fixed half of the die, (b) the effect of intensification pressure parameter $(D)$ and $(c)$ the interaction of parameters $(B)$ and $(D)$. Dash lines are the $95 \%$ confidence intervals.

observed that at all points $\mathrm{R} 1, \mathrm{R} 2$ and $\mathrm{R} 3$ the maximum value of $|\mathrm{SVM}|$ was at the very surface (depth of $0.025-0.05 \mathrm{~mm}$ ) and these stresses were tensile. Moreover, the residual stresses tended toward zero at depths greater than $0.5 \mathrm{~mm}$.

Hofer et al. ${ }^{11}$ suggested that residual stress for HPDC cast parts could be due to cooling and solidification as the solidified surface gains mechanical stability and shrinks. As the interior of the casting solidifies and cools, the initially solidified surface is put under compression. Secondary residual stresses are related to the geometry of the component. ${ }^{21}$ For the mechanism suggested by Hofer et al., ${ }^{11}$ some degree of thermal gradient is required to allow a surface layer to solidify. However, in this study, tensile stress was observed in all cases at the surface. Thermal gradients in a solid layer are characterized by the Biot number, $h L / k$, where $h$ is the heat transfer coefficient, $L$ the characteristic length and $k$ the thermal conductivity. Estimating the Biot number with $h=112 \mathrm{~kW} / \mathrm{m}^{2} \mathrm{~K}$ (at peak value), $k=72 \mathrm{Wm}^{-1} \mathrm{~K}^{-122}$ and $L=0.5 \mathrm{~mm}$ (typical half cross-sectional thickness at the region of interest) leads to a Biot number of 0.77 . This Biot number suggests that there might be a temperature gradient in the surface layer. However, no compressive stress identified at the surface, which means that the magnitude of tensile residual stress at the surface was bigger than the residual stress induced due to the solidification.

From Table 4, it is understood that increasing the intensification pressure led to an increase in tensile residual stress responses at all locations of R1, R2 and R3 at the very surface.

The maximum SVM stress responses for three different points are collated in Table 4. ANOVA of the residual stress (SVM) for points R1, R2 and R3 (Figure 1) is given in Tables 6,7 and 8 respectively.

The parameters (B) and (D) were found statistically significant model terms for residual stress at point R1, see Table 6. Interaction between parameters (B) and (D) was kept to keep model hierarchy as $\left(\mathrm{D}^{2}\right)$ was statistically significant. The effect of temperature of fixed half of the die (B) and intensification pressure (D) on residual stress at point R1 is plotted in Figure 5a, b, respectively. Increasing the temperature of fixed half of the die slightly reduced residual stress at point R1, see Figure 5a. However, an increased intensification pressure strongly increased residual stress at point R1, see Figure $5 b$. The interaction of 


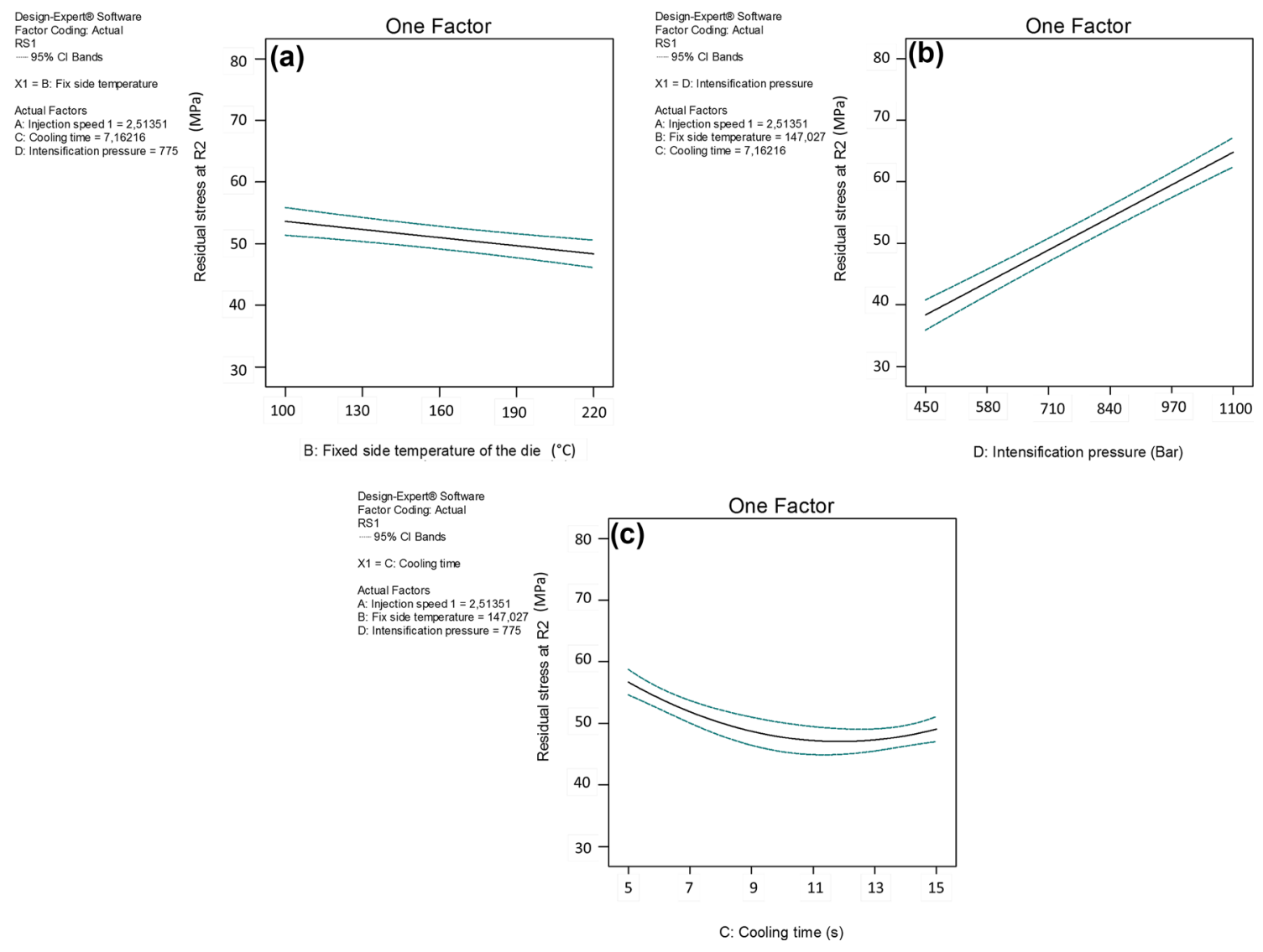

Figure 6. (a) The effect of parameter (B) temperature of fixed half of the die, (b) the effect of intensification pressure parameter $(D)$ and (c) the effect of cooling time on residual stress responses at point R2. Centerline is the actual trend. Dash lines are the $95 \%$ confidence intervals.
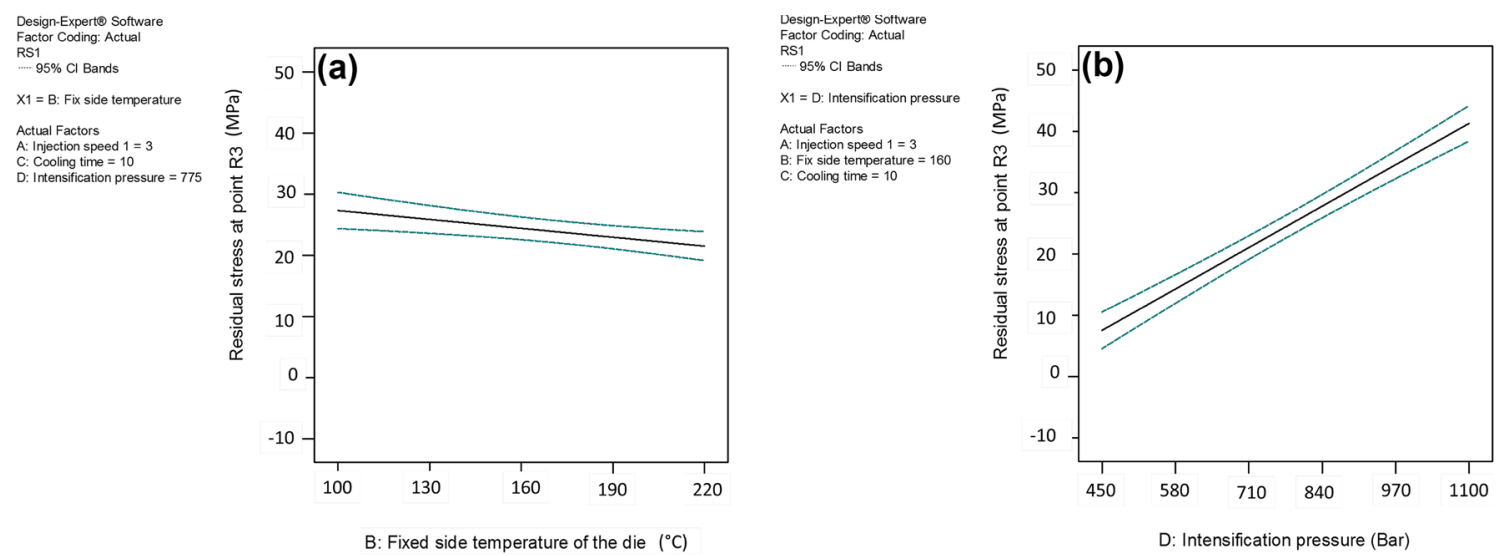

Figure 7. (a) The effect of parameter (B) temperature of fixed half of the die and (b) the effect of intensification pressure parameter (D) on residual stress responses at point R3. Centerline is the actual trend. Dash lines are the $95 \%$ confidence intervals.

parameters (B) and (D) is shown in Figure 5c. The dominating effect is that of the intensification pressure (D). It is worthwhile noting that at low intensification pressure the effect of the temperature of fixed half of the die at residual stress of point R1 was less than at high intensification pressure. At high intensification pressure (D), an increased fixed half temperature (B) reduced residual stress, suggesting that relaxation takes place in contact with the die and that the nature of contact is changed between the die and the component. A similar in-die relaxation was observed by Jarfors ${ }^{23}$ revealing itself as a change in the early-stage hardening in the stress-strain behavior of thinwalled AZ91D test samples.

Table 7 shows ANOVA for residual stress at point R2. Parameters (B), (C), $\left(\mathrm{C}^{2}\right)$ and (D) showed significant effect 
on the model responses. Figure $6 a-c$ shows the effect of temperature of fixed half of the die, cooling time and intensification pressure on the residual stress responses at point R2. Influence of parameters (B) and (D) at point R2 is similar to the point R1 responses. Decreasing the temperature of fixed half of the die and increasing the intensification pressure induced more residual stress at this point. Here, like point R1, the effect of intensification pressure on residual stress was stronger compared to effect of the temperature of fixed half of the die. At point R2, cooling time (C) was statistically significant where an increased cooling time up to $10 \mathrm{~s}$ resulted in less residual stress supporting an in-die relaxation for point R1. Cooling times beyond $10 \mathrm{~s}$ showed no physically significant change in residual stress. It should be noted that the point $\mathrm{R} 2$ is adjacent to the gating system and will experience higher temperature than the rest of the investigated location.

Table 8 shows ANOVA for residual stress at point R3. The parameters (B) and (D) are the significant model terms. Similar to the points R1 and R2, increasing the temperature of fixed half of the die slightly reduced the residual stress, suggesting in-die relaxation. An increased intensification pressure increased the residual stress at this point, see Figure $7 \mathrm{a}, \mathrm{b}$.

Comparing the results from the distortion and residual stress analysis showed that the most dominant parameter was intensification pressure. An increased intensification pressure reduced distortion and increased residual stress near the surface. The distortion showed a maximum on the fixed half of the die when the temperature difference was at a minimum between the two halves. The distortion is toward the fixed side as the geometry of the part is such that it forms a cup around the protruding parts of the fixed side. Residual stress tended to be reduced with increasing moving side temperature supporting an in-die relaxation which also was supported by a reduction of residual stress with increased cooling tome for point R2. It should be noted that the maximum values of SVM were all tensile stress close to the surface $(0.025 \mathrm{~mm}$ depth $)$. Pure solidification from the wall should result in compressive stresses. ${ }^{24}$ This supports that the residual stress formation is dominated by the part lateral contraction and part distortion around the fixed side during cooling, opposing the finding of Hofer et al. ${ }^{11}$

\section{Conclusions}

High-pressure die casting is a complex manufacturing process with many sub-processes or variables. An experimental parametric study was carried out to quantitatively characterize the effects of temperature of fixed half of the die, cooling time, the first-phase injection speed and intensification pressure on the distortion and residual stress formation in the high-pressure die-cast AZ91D Mg alloy.
The collated and presented data lead to the following important observations and conclusions.

The most important process parameter affecting the distortion and residual stress near the surface was intensification pressure. It was clearly observed that increasing the intensification pressure decreased the components' distortion at point D5. Besides, application of intensification pressure significantly increased the residual stress values near the surface.

Significant statistical model for distortion responses were only obtained for distortion results at point D5. It appeared evident that temperature difference between two halves of the die is an important parameter to consider in tolerance management. An increase in the temperature of fixed half of the die increased the total amount of distortion in components, and the distortion is toward the fixed side. On the other hand, increasing the moving side temperature decreased the residual stress of the components due to indie relaxation.

The other two process parameters, first-phase injection speed and cooling time, were found to be relatively less influential.

The obtained maximum SVM was all tensile close to the surface, which means that the residual stress formation is dominated by the part lateral contraction and part distortion around the fixed side during cooling.

The identification of critical process parameters can help foundrymen for better planning the casting process of castings which tend to the formation of distortion and residual stresses.

\section{Acknowledgements}

The authors acknowledge the Knowledge foundation for financial support under CompCAST project (Dnr 2010/0280). Husqvarna AB is also acknowledged for the supply of components and allowing experimental work in the manufacturing line.

Open Access This article is distributed under the terms of the Creative Commons Attribution 4.0 International License ( http://creativecommons.org/licenses/by/4.0/), which permits unrestricted use, distribution, and reproduction in any medium, provided you give appropriate credit to the original author(s) and the source, provide a link to the Creative Commons license, and indicate if changes were made.

\section{REFERENCES}

1. B. Coope, Magnesium in the mainstream. in Resource stocks-magnesium special report (1998), pp. 1-3 
2. B. Mordike, T. Ebert, Magnesium: properties-applications-potential. Mater. Sci. Eng. A 302(1), 37-45 (2001)

3. M.S. Chang, Use of Taguchi method to develop a robust design for the magnesium alloy die casting process. Mater. Sci. Eng. A 379(1), 366-371 (2004)

4. V. Tsoukalas, Optimization of porosity formation in AlSi $9 \mathrm{Cu} 3$ pressure die castings using genetic algorithm analysis. Mater. Des. 29(10), 2027-2033 (2008)

5. R. Lumley, N. Deeva, M. Gershenzon, An evaluation of quality parameters for high pressure die castings. Int. J. Metalcasting 5(3), 37-56 (2011)

6. A.R. Adamane, L. Arnberg, E. Fiorese, G. Timelli, F. Bonollo, Influence of injection parameters on the porosity and tensile properties of high-pressure die cast Al-Si alloys: a review. Int. J. Metalcasting 9(1), 43-53 (2015)

7. S. Lee, A. Gokhale, G. Patel, M. Evans, Effect of process parameters on porosity distributions in highpressure die-cast AM50 Mg-alloy. Mater. Sci. Eng. A 427(1), 99-111 (2006)

8. J.H. Forsmark, J. Boileau, D. Houston, R. Cooper, A microstructural and mechanical property study of an AM50 HPDC magnesium alloy. Int. J. Metalcasting 6(1), 15-26 (2012)

9. B. Yalçin, M. Koru, O. Ipek, A.E. Özgür, Effect of injection parameters and vacuum on the strength and porosity amount of die-casted A380 alloy. Int. J. Metalcasting 11(2), 195-206 (2017)

10. E. Flender, J. Sturm, Thirty years of casting process simulation. Int. J. Metalcasting 4(2), 7-23 (2010)

11. P. Hofer, E. Kaschnitz, P. Schumacher, Distortion and residual stress in high-pressure die castings: simulation and measurements. JOM 66(9), 1638-1646 (2014)

12. G. Campatelli, A. Scippa, A heuristic approach to meet geometric tolerance in high pressure die casting. Simul. Model. Pract. Theory 22, 109-122 (2012)

13. K.-O. Yu, Modeling for Casting and Solidification Processing (CRC Press, Boca Raton, 2001)
14. C. Liu, Z. Lin, Thermal and mechanical stresses in the workpiece during machining. High Speed Mach. 12, 181-191 (1984)

15. J.A. Jacobs, T.F. Kilduff, Engineering Materials Technology: Structures, Processing, Properties, and Selection (Prentice Hall, Upper Saddle River, 2004)

16. H. Hill, J. Zindel, L. Godlewski, Effect of thermal exposure time on the relaxation of residual stress in high pressure die cast AM60. SAE Int. J. Mater. Manuf. 9(2016-01-0423), 653-660 (2016)

17. W. Yu, Y. Cao, X. Li, Z. Guo, S. Xiong, Determination of interfacial heat transfer behavior at the metal/shot sleeve of high pressure die casting process of AZ91D alloy. J. Mater. Sci. Technol. 33(1), 52-58 (2017)

18. Y. Cao, Z. Guo, S. Xiong, Determination of the metal/ die interfacial heat transfer coefficient of high pressure die cast B390 alloy, in IOP Conference Series: Materials Science and Engineering, IOP Publishing, 2012, p. 012010

19. J. Wyatt, J. Berry, A new technique for the determination of superficial residual stresses associated with machining and other manufacturing processes. J. Mater. Process. Technol. 171(1), 132-140 (2006)

20. M. Laakkonen, Residual Stress Measurement of Electron Beam Welded Copper Plates Using Prism Hole Drilling Method (Posiva Oy, Eurajoki, 2013)

21. S. Das, U. Chandra, Residual stress and distortion, in Physical Metallurgy and Processes, ed. by G.E. Totten, D.S. MacKenzie. Handbook of Aluminum, vol. 1 (Marcel Dekker Inc., New York, 2003), pp. 305-349

22. A. Hamasaiid, G. Dour, M. Dargusch, T. Loulou, C. Davidson, G. Savage, Heat-transfer coefficient and incavity pressure at the casting-die interface during highpressure die casting of the magnesium alloy AZ91D. Metall. Mater. Trans. A 39(4), 853-864 (2008)

23. A.E. Jarfors, Yielding and failure of hot chamber die cast thin-walled AZ91D. Metall. Ital. 108(6), 53-56 (2016)

24. H. Fredriksson, U. Åkerlind, Materials Processing During Casting (Wiley, New York, 2006) 